\title{
Baroreflex control of heart rate during sleep in severe obstructive sleep apnoea: effects of acute CPAP
}

\author{
M.R. Bonsignore*,\#, G. Parati ${ }^{{ }^{\top},+}$, G. Insalaco ${ }^{\#}$, P. Castiglioni $^{\S}$, O. Marrone ${ }^{\#}$, \\ S. Romano", A. Salvaggio", G. Mancia", G. Bonsignore ${ }^{\#}$ and M. Di Rienzo ${ }^{\S}$
}

ABSTRACT: Baroreflex control of heart rate during sleep (baroreflex sensitivity; BRS) has been shown to be depressed in obstructive sleep apnoea (OSA), and improved after treatment with continuous positive airway pressure (CPAP). Whether CPAP also acutely affects BRS during sleep in uncomplicated severe OSA is still debatable.

Blood pressure was monitored during nocturnal polysomnography in 18 patients at baseline and during first-time CPAP application. Spontaneous BRS was analysed by the sequence method, and estimated as the mean sequence slope.

CPAP did not acutely affect mean blood pressure or heart rate but decreased cardiovascular variability during sleep. Mean BRS increased slightly during CPAP application (from $6.5 \pm 2.4$ to $7.5 \pm 2.9 \mathrm{~ms} \cdot \mathrm{mmHg}^{-1}$ ), mostly in response to decreasing blood pressure. The change in BRS did not correlate with changes in arterial oxygen saturation or apnoea/hypopnoea index.

The small change in baroreflex control of heart rate during sleep at first application of continuous positive airway pressure in severe obstructive sleep apnoea was unrelated to the acute resolution of nocturnal hypoxaemia, and might reflect autonomic adjustments to positive intrathoracic pressure, and/or improved sleep architecture. The small increase in baroreflex control of heart rate during sleep may be of clinical relevance as it was accompanied by reduced cardiovascular variability, which is acknowledged as an independent cardiovascular risk factor.

KEYWORDS: Baroreceptors, blood pressure, hypoxia, positive intrathoracic pressure, sleep

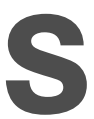
evere obstructive sleep apnoea (OSA) is a known cause of autonomic dysfunction [1-6] and increased cardiovascular risk and mortality [7, 8]. Long-term treatment with continuous positive airway pressure (CPAP) is effective in counteracting the detrimental effects of OSA on the cardiovascular system. In addition, baroreflex control of heart rate was found to increase $[1,4,5]$ sympathetic and hyperactivity decreased $[9,10]$, after prolonged CPAP treatment.

All studies of the effects of acute CPAP application in OSA patients agree that preventing apnoeas by effective CPAP decreases cardiovascular variability [9-13]. Conversely, the effects of acute CPAP on systemic arterial blood pressure (BP) levels are still controversial [9-13], and may be more readily apparent in hypertensive subjects [14]. Little is known about the effects of first CPAP application on baroreflex function in previously untreated patients with uncomplicated OSA. Acute CPAP application in normal awake subjects breathing at 12 or 15 breaths. $\mathrm{min}^{-1}$ caused bradycardia, and increased BP and the high-frequency component of the alpha index (a measure of the sensitivity of baroreflex cardiac modulation in the frequency domain) of baroreflex gain [15]. Conversely, in patients with OSA and chronic heart failure (CHF), CPAP application during sleep increased spontaneous baroreflex control of heart rate (baroreflex sensitivity; BRS) but decreased BP in nonrapid eye movement (NREM) stage 2 sleep [16]. Acute CPAP also improved BRS and decreased BP in patients with OSA and refractory hypertension [14]. Finally, short-term (7-10 days) CPAP treatment increased BRS during NREM sleep in nonapnoeic snorers to levels found in nonsnorer controls [17].

To the current authors' knowledge, no study has assessed the effects of acute CPAP application on baroreflex control of heart rate during sleep in patients with severe uncomplicated OSA. The aim of the present study was to fill this gap. Specifically, the relationship between

\section{AFFILIATIONS}

*Institute of Medicine and Pneumology, University of Palermo, and

\# Institute of Biomedicine and Molecular Immunology (IBIM), National Research Council (CNR), Palermo

- Clinica Medica, Milano-Bicocca University,

${ }^{+}$Cardiology II, S. Luca Hospital, Istituto Auxologico Italiano,

${ }^{\S}$ Centro di Bioingegneria, Fondazione Don C. Gnocchi, Milan, Italy.

CORRESPONDENCE

M.R. Bonsignore

Institute of Medicine and

Pneumology

University of Palermo

Via Trabucco, 180

Palermo

Italy

Fax: 390916802165

E-mail: marisa@ibim.cnr.it

Received:

April 132004

Accepted after revision:

September 282005

SUPPORT STATEMENT

This study was supported by CNRItaly and ICS grant number 030.7/RF 00.80 .

European Respiratory Journal Print ISSN 0903-1936 Online ISSN 1399-3003 
CPAP-induced acute correction of nocturnal intermittent hypoxaemia and changes in baroreflex control of heart rate was investigated. Based on the direct relationship between mean lowest arterial oxygen saturation $\left(\mathrm{Sa}_{2} \mathrm{O}_{2}\right)$ during NREM sleep and BRS previously shown in untreated severe OSA [1], the current authors hypothesised that resolution of nocturnal intermittent hypoxaemia by CPAP might acutely improve baroreflex control of heart rate, as already demonstrated in the case of chronic treatment.

\section{PATIENTS AND METHODS \\ Subjects}

The study was conducted in 18 male patients with severe OSA (table 1). Inclusion criteria were: normal daytime BP $(<120 /$ $80 \mathrm{mmHg})$ or mild untreated hypertension $(<145 / 95 \mathrm{mmHg})$ at repeated office $\mathrm{BP}$ measurements; no evidence of heart failure or other disease causing autonomic dysfunction; no treatment with cardiovascular drugs; and normal pulmonary function. Alcohol and caffeine intake were $<30 \mathrm{~g} \cdot \mathrm{day}^{-1}$, and 24 cups $\cdot$ day $^{-1}$, respectively. Ten patients were current smokers (cigarettes $\cdot$ day $^{-1}:<20: n=8 ; \geqslant 20: n=2$ ). All subjects refrained from caffeine, alcohol and smoking on the days of the study.

Patients were studied at baseline and during CPAP titration. CPAP studies were performed $18 \pm 9$ days after baseline study (range 1-30 days). During this interval, no patient received any treatment, or changed weight or smoking habits. CPAP was titrated manually. From the nasal mask, the pressure applied was continuously measured by a pressure transducer while flow was sampled and integrated by a pneumotachograph to detect apnoeas, hypopnoeas and inspiratory flow limitation. The CPAP level was considered appropriate when respiratory events, including flow limitation episodes, were abolished in all sleep stages in the supine position. The data analysed were obtained after an effective CPAP level was attained. Subjects gave their informed consent, and the study protocol was approved by the local ethical committee.

\section{Measurements and data analysis}

The protocol of night studies has been reported previously [1]. During full nocturnal polysomnography (Somnostar 4100; SensorMedics Corporation, Yorba Linda, CA, USA), arterial BP was noninvasively monitored on a beat-by-beat basis (Finapres 2300, autocalibration mode; Ohmeda, Englewood, CO, USA). Finger-cuff inflation was stopped for 5 min every $40 \mathrm{~min}$ to prevent finger discomfort during the recording. The hand equipped with the Finapres cuff was held in a constant position at heart level.

Sleep was scored in 30-s epochs [18]. Epochs of NREM stages 1 and 3-4, and epochs without BP recording (periodic interruption, Finapres calibration, or BP artefacts) were not analysed.

Apnoea was defined as an interruption of airflow $\geqslant 10 \mathrm{~s}$, and scored as obstructive or central according to persistence or absence of thoraco-abdominal movements, respectively. Hypopnoea was defined as a decrease in airflow $\geqslant 50 \%$, associated with arousal and/or decreased $\mathrm{Sa}_{2} \mathrm{O}_{2} \geqslant 4 \%$. Apnoea/hypopnoea index $(\mathrm{AHI})$, mean $\mathrm{Sa}_{1} \mathrm{O}_{2}$ during wakefulness, and mean lowest $\mathrm{Sa}_{2} \mathrm{O}_{2}$ in NREM stage 2 and REM sleep were calculated.

Cardiovascular variables were analysed by considering 2-min segments showing a stable polysomnographic stage [18] and good quality BP signal for $\geqslant 85 \%$ of their duration [1]. Analysed sleep segments showed recurrent apnoeas at baseline, and regular unobstructed breathing during CPAP as indirectly confirmed by the absence of snoring and of pulsus

TABLE 1 Anthropometric and sleep data

$\begin{array}{llll}\text { No treatment } & & \begin{array}{c}\text { Acute CPAP } \\ \text { OSA all }\end{array}\end{array}$

\section{Patients $n$}

Age yrs

Body mass index $\mathrm{kg} \cdot \mathrm{m}^{-2}$

Office systolic BP $\mathrm{mmHg}$

Office diastolic BP $\mathrm{mmHg}$

Apnoea/hypopnoea index $n \cdot h^{-1}$

BP recording time min

Nocturnal wakefulness \% of BP recording

time $^{+}$

NREM stage 2 sleep \% of BP recording time ${ }^{+}$

NREM stage 3-4 sleep \% of BP recording time ${ }^{+}$

REM sleep \% of BP recording time ${ }^{+}$

$\mathrm{Sa}, \mathrm{O}_{2}$ during wakefulness $\%$

Mean lowest $\mathrm{Sa}, \mathrm{O}_{2}$ NREM sleep \%

Mean lowest $\mathrm{Sa}, \mathrm{O}_{2}$ REM sleep \%
10

$42.7 \pm 7.1$

$36.8 \pm 4.6$

$135.0 \pm 8.7$

$87.7 \pm 5.7$

$81 \pm 12$

$272 \pm 59$

$17.0 \pm 9.9$

$62.6 \pm 10.8$

$0.9 \pm 2.7$

$8.2 \pm 4.5$

$95.3 \pm 1.3$

$76.7 \pm 6.9$

$60.6 \pm 11.2$
8

$45.0 \pm 10.5$

$33.7 \pm 7.6$

$127.5 \pm 11.3$

$80.0 \pm 7.1^{\#}$

$78 \pm 27$

$280 \pm 48$

$12.3 \pm 5.8$

$67.8 \pm 13.0$

$4.2 \pm 7.4$

$8.6 \pm 4.7$

$96.0 \pm 1.3$

$84.9 \pm 4.4^{\#}$

$71.5 \pm 12.9$
18

$$
\begin{gathered}
43.7 \pm 8.6 \\
35.5 \pm 6.1 \\
131.5 \pm 10.4 \\
84.1 \pm 7.3
\end{gathered}
$$

$\begin{array}{cc}80 \pm 20 & 4 \pm 3 \\ 275 \pm 53 & 157 \pm 50 \\ 14.9 \pm 8.5 & 12.7 \pm 16.0\end{array}$

$64.9 \pm 11.8$

$2.4 \pm 5.4$

$8.4 \pm 4.4$

$95.7 \pm 1.3$

$80.2 \pm 7.3$

$64.9 \pm 13.0$
18

$51.2 \pm 18.1^{\bullet}$

$13.9 \pm 15.0^{\circ}$

$20.1 \pm 14.3^{\circ}$

$96.2 \pm 1.4$

$95.8 \pm 1.4$

$95.3 \pm 1.6$

BP: blood pressure; CPAP: continuous positive airway pressure; OSA: obstructive sleep apnoea; REM: rapid eye movement; NREM: nonrapid eye movement; $\mathrm{Sa}, \mathrm{O}_{2}$ : arterial oxygen saturation. ${ }^{+}$: sum of \% BP recorded time is $<100$ because NREM stage 1 sleep is not reported (see Methods); ${ }^{\#}$ : $\mathrm{p}<0.05$ versus smokers (unpaired t-test); ${ }^{\prime}: p<0.05$ between baseline and acute CPAP application (paired t-test). 
paradoxus on the BP signal. Mean systolic (S) and diastolic (D) $\mathrm{BP}$ and pulse interval (PI), and their standard deviations (SD) taken as estimates of variability, were calculated during nocturnal wakefulness, NREM stage 2 and REM sleep.

Baroreflex function was analysed according to the sequence method described in detail elsewhere [1, 2, 19-22]. Spontaneous sequences of three or more consecutive beats in which PI and SBP progressively increased $(+\mathrm{PI} /+\mathrm{SBP}$, up sequences) or decreased (-PI/-SBP, down sequences) were identified. BRS was assessed as the slope of the regression line between PI and SBP values within each sequence. Mean BRS, the number of sequences per hour (sequence index), and mean SBP and PI at beginning and end of sequences were calculated in each stage.

\section{Statistics}

Data are reported as mean $\pm \mathrm{SD}$. Unpaired t-test was used to compare variables between smoking and nonsmoking OSA patients. Paired t-test was used to compare variables recorded under no treatment and under CPAP, separately for the considered sleep stages. Differences among sleep stages in each condition were tested by ANOVA with Bonferroni's correction. Relationships between variables were analysed by linear regression. Statistical significance was set at $\mathrm{p}<0.05$.

\section{RESULTS}

\section{Demographic and sleep data}

The patients studied were on average middle-aged, obese, and most $(n=11)$ showed slightly increased BP values during wakefulness (table 1). Their OSA was severe, as indicated by an $\mathrm{AHI}$ ranging between 58 and 143 events $\cdot \mathrm{h}^{-1}$ and low $\mathrm{Sa}, \mathrm{O}_{2}$ values during sleep. Pulmonary function tests during daytime were in the normal range (group means for forced expiratory volume in one second and forced vital capacity were $102.0 \pm 17.5 \%$ and $104.1 \pm 17.8 \%$ of predicted values, respectively), and mean $\mathrm{Pa}_{1} \mathrm{O}_{2}$ and $\mathrm{Pa}_{\mathrm{a}} \mathrm{CO}_{2}$ were $10.9 \pm 1.3$ and $5.57 \pm 0.4 \mathrm{kPa}$, respectively.

Mean age, body mass index (BMI), spirometry, AHI or sleep stage distribution did not differ between smoking and nonsmoking patients. Mean $\mathrm{Pa}_{1} \mathrm{O}_{2}$ during wakefulness was lower in smokers $(9.92 \pm 0.69 \mathrm{kPa})$ than in nonsmokers $(1.58 \pm 0.2 \mathrm{kPa}, \mathrm{p}<0.005)$. Diastolic BP during wakefulness was significantly higher, while mean $\mathrm{Sa}_{1} \mathrm{O}_{2}$ during NREM sleep was significantly lower in smokers than in nonsmokers (table 1).

The level of CPAP applied during the study was $11.2 \pm 3.0$ $\mathrm{cmH}_{2} \mathrm{O}$. CPAP prevented obstructive events and normalised $\mathrm{Sa}_{\mathrm{a}} \mathrm{O}_{2}$ during sleep in all patients independent of their smoking status. Compared with the baseline study, the amount of stage 2 NREM sleep decreased, and that of REM sleep increased during CPAP application. NREM stage 3-4 sleep was recorded for very short periods in seven OSA patients at baseline, and in 12 patients during CPAP application, preventing satisfactory analysis of BRS in this sleep stage.

\section{Blood pressure and pulse interval}

The average number of 2-min segments analysed under no treatment and during CPAP application, respectively, were: $10 \pm 7$ and $21 \pm 11$ for nocturnal wakefulness, $65 \pm 21$ and
$36 \pm 16$ for NREM stage 2 sleep, $11 \pm 7$ and $15 \pm 16$ for REM sleep. Mean SBP tended to decrease during CPAP application, while DBP and PI did not differ between studies in any sleep stage (table 2). The variability of SBP, DBP and PI during sleep, estimated as their SD, decreased markedly during CPAP (table 2).

SBP and DBP values during sleep were similar in smokers and nonsmokers under no treatment and during CPAP application. Instead, cardiovascular variability during wakefulness and sleep was significantly higher in smokers compared with nonsmoker OSA patients under no treatment; this difference disappeared during CPAP application. For example, SD of SBP during the entire polysomnographic study under no treatment was $15.3 \pm 4.2 \mathrm{mmHg}$ in smokers and $12.2 \pm 2.7 \mathrm{mmHg}$ in nonsmokers $(\mathrm{p}<0.01)$. Corresponding values during CPAP were $6.1 \pm 1.5$ and $6.5 \pm 1.4 \mathrm{mmHg}$ (nonsignificant). DBP and PI variability were also increased in smoking OSA patients under no treatment only (not shown).

\begin{tabular}{|c|c|c|c|}
\hline \multirow{2}{*}{$\begin{array}{l}\text { TABLE } 2 \\
\text { Sleep stage }\end{array}$} & \multicolumn{3}{|c|}{$\begin{array}{l}\text { Mean systolic and diastolic blood pressure (SBP } \\
\text { and DBP) and pulse interval (PI), and their } \\
\text { variability (standard deviation) in the entire group } \\
(n=18)\end{array}$} \\
\hline & $\begin{array}{c}\text { Nocturnal } \\
\text { wakefulness }\end{array}$ & NREM stage 2 & REM \\
\hline \multicolumn{4}{|c|}{ Mean SBP mmHg } \\
\hline No treatment & $132.5 \pm 13.3$ & $133.1 \pm 13.6$ & $143.4 \pm 18.9$ \\
\hline Acute CPAP & $134.3 \pm 18.3$ & $127.8 \pm 19.2$ & $134.2 \pm 20.8$ \\
\hline $\mathrm{p}$-value & NS & NS & NS \\
\hline \multicolumn{4}{|c|}{ SD of SBP $\mathrm{mmHg}$} \\
\hline No treatment & $11.2 \pm 4.0^{\#}$ & $15.3 \pm 3.5$ & $14.7 \pm 3.4$ \\
\hline Acute CPAP & $7.8 \pm 1.1^{\#}$ & $5.7 \pm 1.3$ & $5.9 \pm 1.2$ \\
\hline $\mathrm{p}$-value & NS & $<0.0001$ & $<0.0001$ \\
\hline \multicolumn{4}{|c|}{ Mean DBP mmHg } \\
\hline No treatment & $77.8 \pm 9.0$ & $74.7 \pm 8.9$ & $81.2 \pm 10.4$ \\
\hline Acute CPAP & $78.3 \pm 9.8$ & $75.7 \pm 9.8$ & $77.6 \pm 10.7$ \\
\hline$p$-value & NS & NS & NS \\
\hline \multicolumn{4}{|c|}{ SD of DBP $\mathrm{mmHg}$} \\
\hline No treatment & $6.7 \pm 2.0^{\circ}$ & $9.0 \pm 2.0$ & $9.5 \pm 2.4$ \\
\hline Acute CPAP & $4.6 \pm 0.9^{\#}$ & $3.3 \pm 0.7$ & $3.5 \pm 0.9$ \\
\hline$p$-value & $<0.05$ & $<0.0001$ & $<0.0001$ \\
\hline \multicolumn{4}{|l|}{ Mean PI ms } \\
\hline No treatment & $769 \pm 99^{\circ}$ & $840 \pm 102$ & $871 \pm 99$ \\
\hline Acute CPAP & $846 \pm 124$ & $862 \pm 133$ & $851 \pm 136$ \\
\hline$p$-value & NS & NS & NS \\
\hline \multicolumn{4}{|l|}{ SD of PI ms } \\
\hline No treatment & $56 \pm 19^{\#}$ & $88 \pm 32$ & $117 \pm 62$ \\
\hline Acute CPAP & $52 \pm 18$ & $36 \pm 14$ & $37 \pm 16$ \\
\hline$p$-value & NS & $<0.0001$ & $<0.0001$ \\
\hline
\end{tabular}

The $p$-values refer to paired t-test applied to no treatment and acute continuous positive airway pressure (CPAP) data in each column. NREM: nonrapid eye movement; REM: rapid eye movement. ${ }^{\#}$ : wakefulness significantly different from NREM stage 2 and REM sleep (ANOVA to test differences among sleep stages); ${ }^{\uparrow}$ : wakefulness significantly different from REM sleep; $p$-value $<0.05$ in all comparisons. 


\section{Baroreflex sensitivity}

In the baseline night, mean BRS during wakefulness was lower in smokers compared with nonsmokers (smokers: $4.8 \pm 1.9 \mathrm{~ms} \cdot \mathrm{mmHg}^{-1}$; nonsmokers: $\quad 7.2 \pm 1.2 \mathrm{~ms} \cdot \mathrm{mmHg}^{-1}$, $\mathrm{p}<0.01)$. Differences in BRS during sleep did not reach significance (NREM stage 2: smokers $5.4 \pm 2.3 \mathrm{~ms} \cdot \mathrm{mmHg}^{-1}$, nonsmokers $7.2 \pm 1.3 \mathrm{~ms} \cdot \mathrm{mmHg}^{-1}, \mathrm{p}=0.07$; REM: smokers $7.9 \pm 3.0 \mathrm{~ms} \cdot \mathrm{mmHg}^{-1}$, nonsmokers $7.4 \pm 2.7 \mathrm{~ms} \cdot \mathrm{mmHg}^{-1}$, nonsignificant). During CPAP application, mean BRS increased from $6.5 \pm 2.4$ to $7.5 \pm 2.9 \mathrm{~ms} \cdot \mathrm{mmHg}^{-1}(\mathrm{p}<0.05)$, without differences between normotensive and slightly hypertensive patients or according to smoking status (not shown).

When sequences characterised by baroreflex activation (+PI/ $+\mathrm{SBP})$ and deactivation (-PI/-SBP) were analysed separately (fig. 1 and 2), OSA patients under no treatment showed a higher mean sequence slope in $+\mathrm{PI} /+\mathrm{SBP}$ than in $-\mathrm{PI} /-\mathrm{SBP}$ sequences (7.9 \pm 4.5 versus $\left.5.9 \pm 2.6 \mathrm{~ms} \cdot \mathrm{mmHg}^{-1}, \quad \mathrm{p}<0.01\right)$. Acute CPAP application increased only the slope of -PI/-SBP sequences without differences according to the smoking status (fig. 1 and 2). The number of sequences per hour was unaffected by CPAP (figure 3).

The mean range of SBP changes during baroreflex sequences (table 3) decreased from the baseline night (+PI/+SBP:
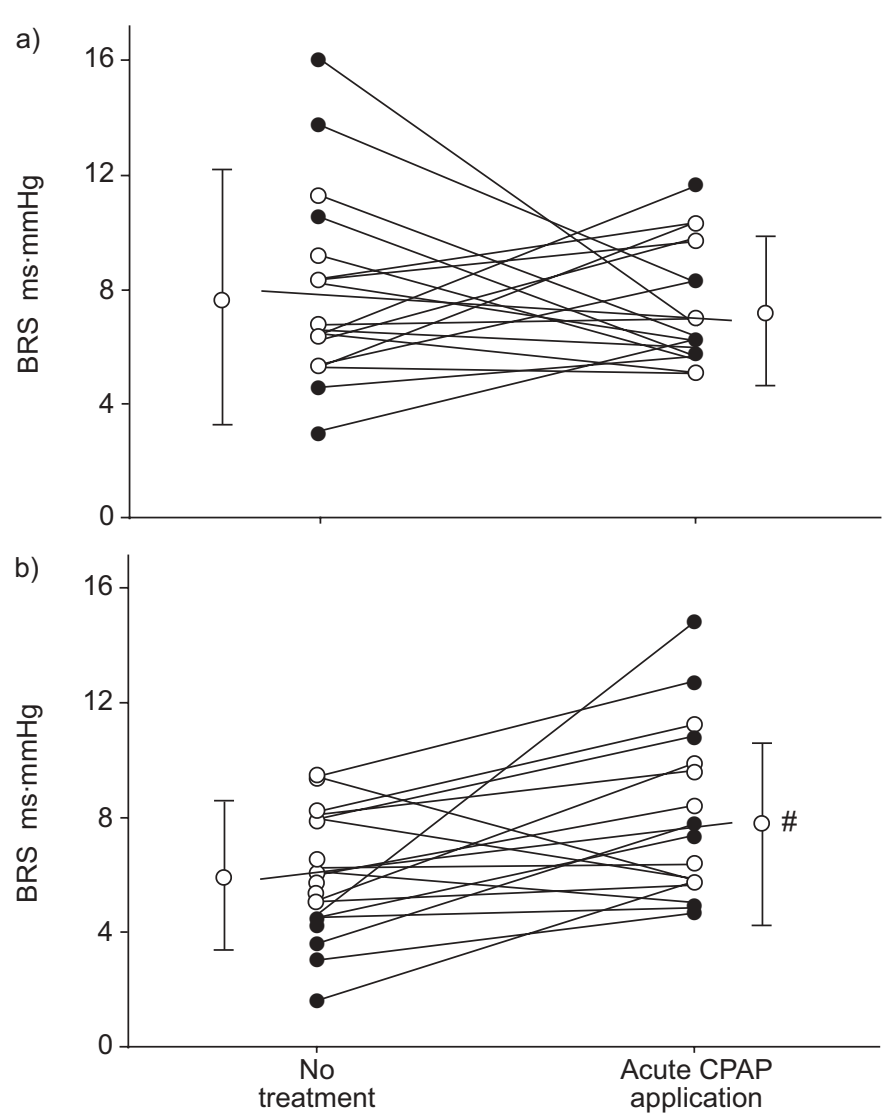

FIGURE 1. Individual $(\bigcirc$ : nonsmokers;

smokers) and mean (outermost symbols $\pm \mathrm{SD}$ ) spontaneous baroreflex control of heart rate (BRS) for the analysed recordings obtained under no treatment and during acute continuous positive airway pressure (CPAP) application. a) shows baroreflex activation sequences; and b) shows baroreflex deactivation. ${ }^{*}$ : significant difference compared with baseline.
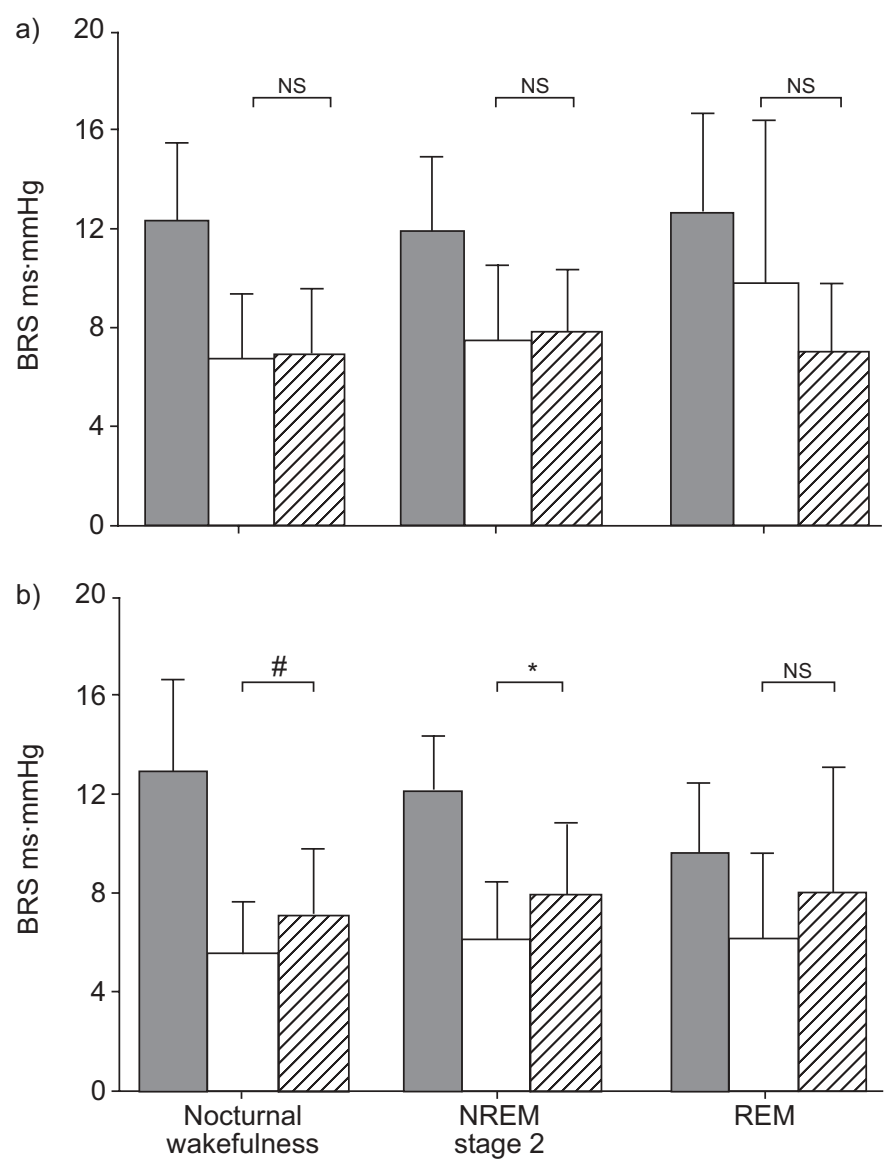

FIGURE 2. Spontaneous baroreflex control of heart rate (BRS) in obstructive sleep apnoea patients at different sleep stages (nocturnal wakefulness, nonrapid eye movement (NREM) and rapid eye movement (REM)). Continuous positive airway pressure (CPAP) application did not modify BRS in +PI/+SBP sequences (a), but increased BRS slightly in -PI/-SBP sequences (b). Statistical analysis was by paired t-test in each sleep stage. $\square$ : under no treatment; $\square$ : during acute application of CPAP; $\mathbf{\square}$ : control subjects (data from [1]).

$14.7 \pm 2.6 \mathrm{mmHg}$; -PI/-SBP: $17.3 \pm 4.8 \mathrm{mmHg}$ ) to the CPAP night (+PI/+SBP: $11.4 \pm 3.1 \mathrm{mmHg} ; \quad$-PI/-SBP: $10.5 \pm 4.1 \mathrm{mmHg}$, $\mathrm{p}<0.0001$ for both comparisons), especially in smoker OSA patients who showed a high cardiovascular variability under no treatment. Mean PI at the beginning of $+\mathrm{PI} /+\mathrm{SBP}$ sequences increased significantly during wakefulness and NREM stage 2 sleep (table 3).

Although average PI values during sleep did not differ significantly between studies (table 2), the changes in BRS from baseline to CPAP application were positively correlated with development of bradycardia during NREM stage 2 sleep assessed as the change in mean PI $(+\mathrm{PI} /+\mathrm{SBP}$ sequences: $\mathrm{r}=0.70, \mathrm{p}<0.005 ; \quad-\mathrm{PI} /-\mathrm{SBP}$ sequences: $\mathrm{r}=0.78, \mathrm{p}=0.001$ ). Instead, no correlation was found between the change in BRS and baseline AHI or the change in mean lowest $\mathrm{Sa}_{1} \mathrm{O}_{2}$ during sleep on CPAP (fig. 4).

\section{DISCUSSION}

The main result of the current study shows that in patients with uncomplicated severe OSA, acute application of CPAP during sleep prevented apnoeas and intermittent hypoxaemia, 

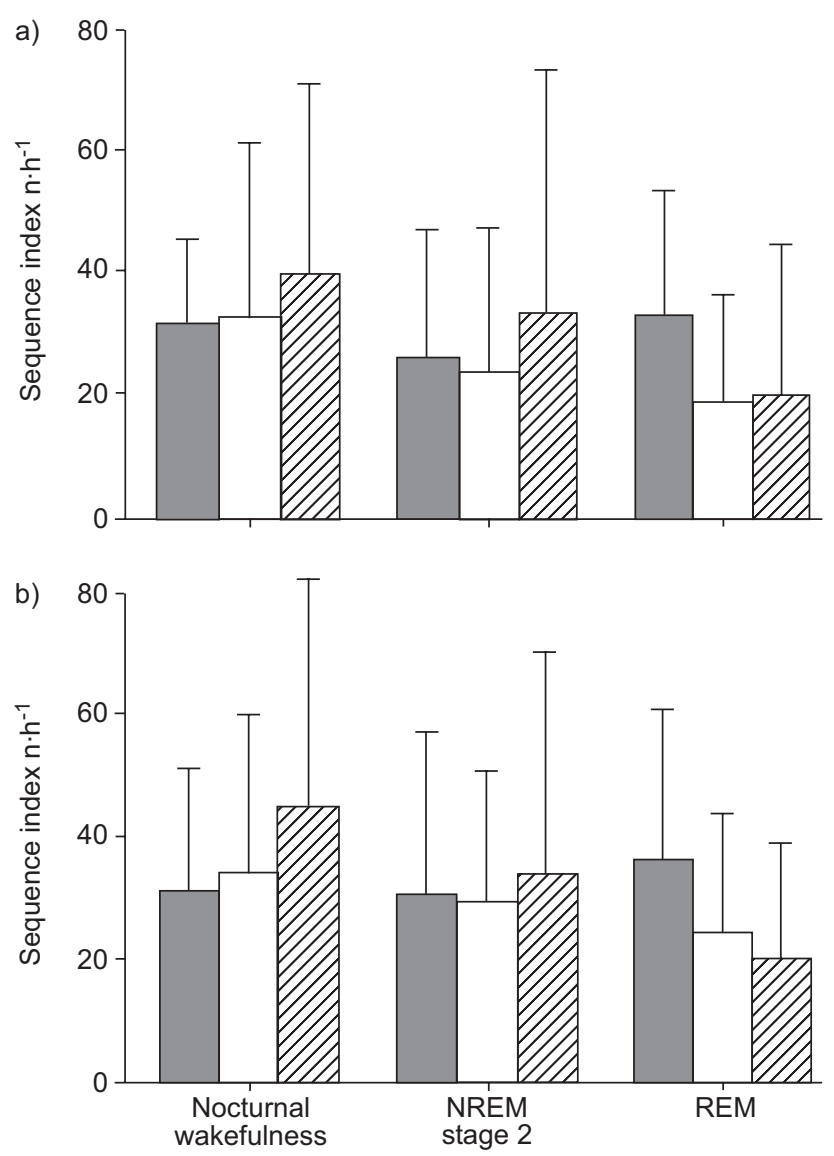

FIGURE 3. Sequence index (number of sequences $\cdot h^{-1}$ ) in obstructive sleep apnoea (OSA) patients at different sleep stages (nocturnal wakefulness, nonrapid eye movement (NREM) and rapid eye movement (REM)). All comparisons between baseline and acute continuous positive airway pressure (CPAP) application conditions were not significant. $\square$ : under no treatment; ${ }^{-1}$ : during acute application of CPAP; : : control subjects (data from [1]).

induced a significant and marked reduction in cardiovascular variability, and was responsible for a small but significant improvement in baroreflex control of heart rate, mostly in response to baroreceptor deactivation (down sequences). This improvement in BRS was smaller than BRS changes observed after prolonged CPAP treatment [1] and did not correlate with the increase in $\mathrm{Sa}_{1} \mathrm{O}_{2}$ during sleep. Therefore, the current authors' hypothesis that acute correction of nocturnal intermittent hypoxaemia might be associated with an acute improvement of BRS in patients with severe uncomplicated OSA was only partly confirmed. Full recovery of reflex cardiac modulation in severe OSA patients undergoing CPAP ventilation during sleep might require prolonged regular treatment.

However, other aspects of the current study deserve to be discussed. First, about half of our subjects were smokers, and this may have affected the results, as smoking is known to decrease BRS [23-25]. Smokers and nonsmokers were comparable for anthropometric variables and AHI, but smokers were slightly hypoxaemic during wakefulness and showed a lower $\mathrm{Sa}_{1} \mathrm{O}_{2}$ during sleep, lower BRS values during wakefulness, and a larger cardiovascular variability under no treatment conditions. This is in line with previous data on the cardiovascular

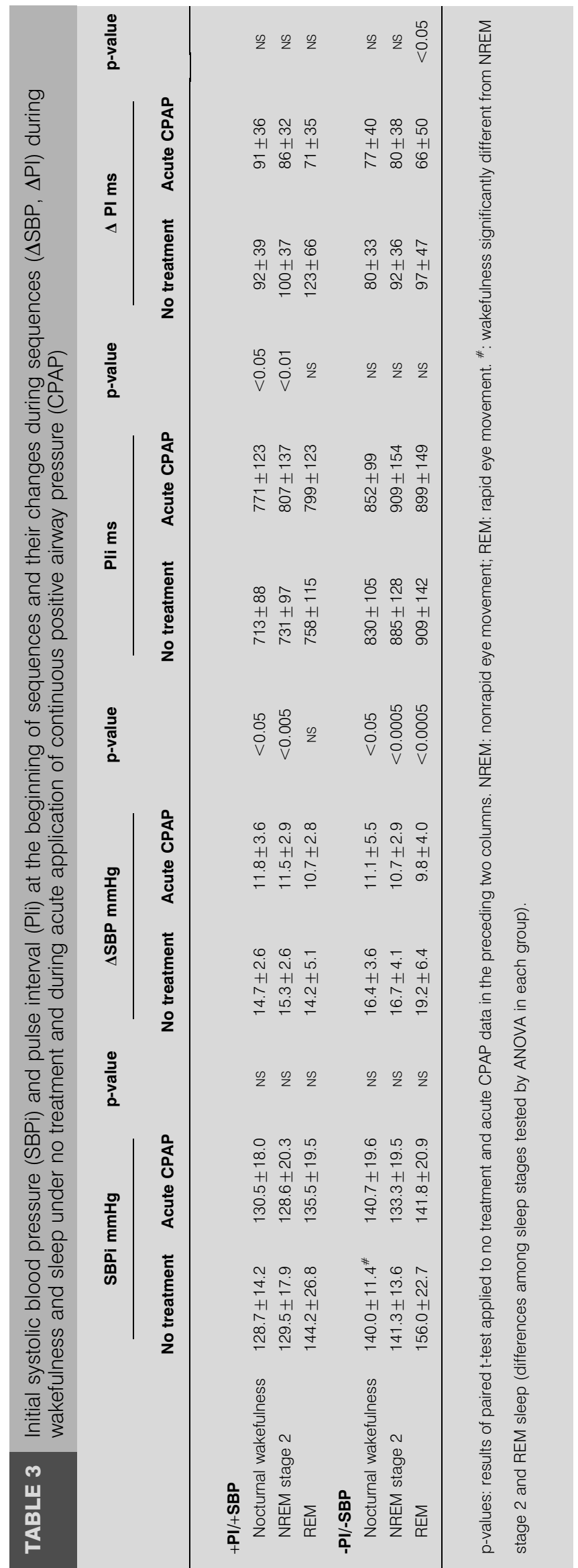



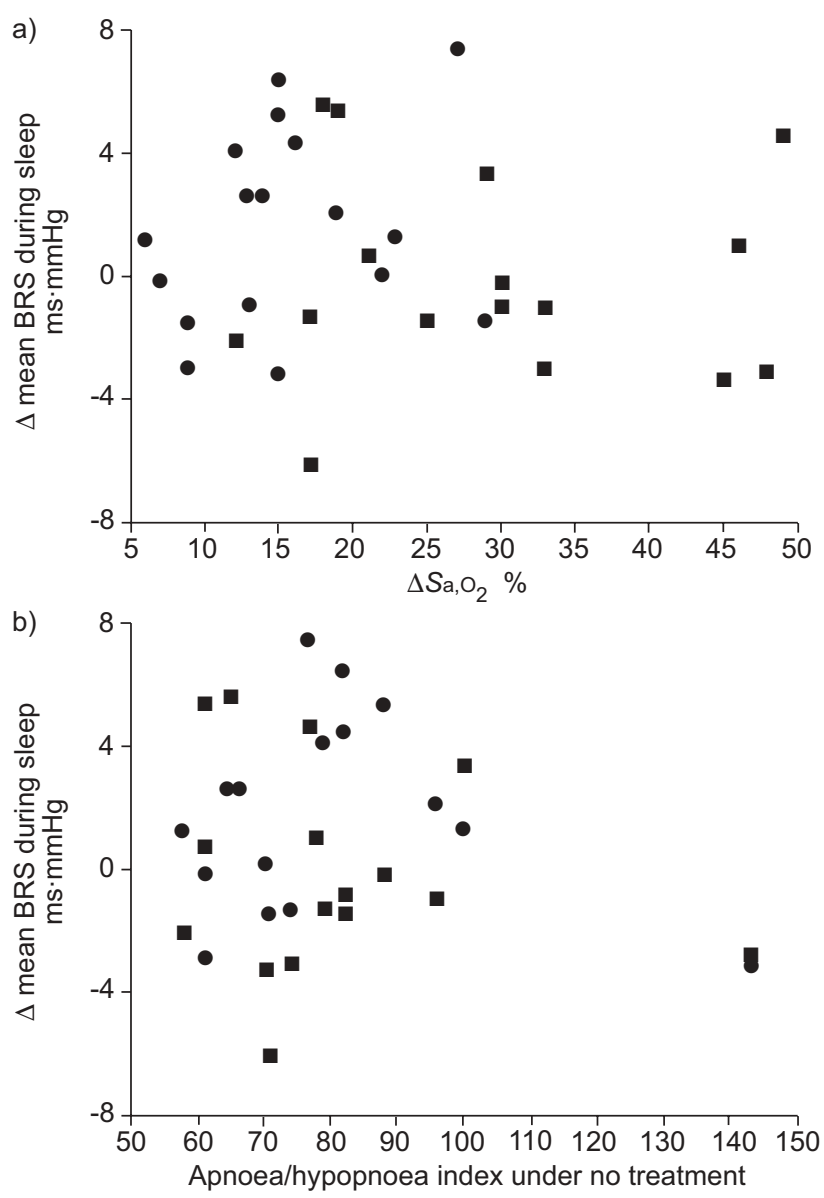

FIGURE 4. Changes in mean baroreflex sensitivity (BRS) during continuous positive airway pressure application versus changes in arterial oxygen saturation $\left(\triangle \mathrm{Sa}, \mathrm{O}_{2}\right)$ during sleep (a) and baseline apnoea/hypopnoea index (b). All correlations were not significant $\left(r^{2}: 0.055\right.$ and 0.003 for $\mathrm{Sa}, \mathrm{O}_{2} ; 0.013$ and 0.039 for apnoea/ hypopnoea index, in nonrapid eye movement $(\bullet)$ and rapid eye movement sleep (匹), respectively).

effects of cigarette smoking, which appear to characterise only the actual smoking period during the daytime and fade away 15-20 min after the last cigarette and in the absence of smoking during night-time sleep [26, 27]. In fact, the effects of CPAP application did not differ between smoking and nonsmoking OSA patients, and the two groups no longer differed during CPAP application. However, further studies are necessary to explore this point given the strong impact of both smoking and OSA on cardiovascular risk [8].

Secondly, the acute application of CPAP did not affect mean $\mathrm{BP}$ and PI values, which is in line with previous observations [9-13]. However, at variance with previous studies including hypertensive patients, in the current study only normotensive and mildly hypertensive untreated patients were recruited. The results therefore support the notion that CPAP may decrease BP mostly in patients with sleep-disordered breathing associated with a frank hypertensive condition [9, 14, 28]. On the other hand, in line with previous studies [2], the data provide clear evidence that acute CPAP blunts the increase in cardiovascular variability from wakefulness to sleep typical of untreated OSA [1]. This finding was also evident when focusing on the beat-by-beat SBP changes (SBP ramps), characterising spontaneous baroreflex sequences, since the range of SBP fluctuations during either up or down sequences, respectively leading to baroreceptor activation or deactivation, was clearly reduced during CPAP application.

The similar BP levels observed during the baseline and CPAP nights might depend on different pathophysiological mechanisms. The current authors speculate that under no treatment, BP mostly reflected OSA-associated cardiovascular perturbations [1]; however, during CPAP application peripheral vasoconstriction evoked by reflex reaction to positive intrathoracic pressure may predominate [29-31]. This interpretation is supported by the evidence that application of low levels of positive pressure ventilation in normal awake subjects increased diastolic BP [15]. Similarly, baroreceptor-mediated adjustments were shown to occur in response to increased intrathoracic pressure [29, 30]. Finally, in normal awake humans, CPAP at 10-12 $\mathrm{cmH}_{2} \mathrm{O}$ decreased central blood volume and redistributed cardiac output without affecting arterial BP or heart rate; however, calf resistance increased, indicating active autonomic adjustments on peripheral circulation [31]. Thus, similar autonomic adjustments may have occurred in the normotensive or marginally hypertensive OSA patients in response to $\mathrm{CPAP}$, and might have accounted for the apparent paradox of little or no change in BP despite normalisation of respiration, reduction in cardiovascular variability $[1,2]$ and reduction in muscle sympathetic nerve activity [10] already occurring at the time of the first CPAP application during sleep.

In the normotensive and marginally hypertensive subjects, an increase in BRS during CPAP application was found without associated changes in $\mathrm{BP}$ or heart rate, at variance with the data obtained in subjects with OSA combined with refractory hypertension [14], or in patients with OSA and CHF [16]. Differences in methods may partly explain these different results, as the data were obtained at first CPAP application, whereas hypertensive and $\mathrm{CHF}$ patients were studied after one or more treatment nights. Moreover, the larger effects recorded in patients with CHF and OSA may be due to positive haemodynamic changes exerted by CPAP in this context [3235] besides the prevention of upper airway obstruction.

A third issue to be addressed is the finding that the significant albeit small increase in BRS during acute CPAP application was associated with decreased heart rate, suggesting improved parasympathetic and reduced sympathetic cardiac modulation. FiETZE et al. [15] found that both the high frequency component of heart rate variability (commonly regarded as an indirect marker of parasympathetic cardiac modulation) and the so called "alpha index" (another measure of the sensitivity of baroreflex cardiac modulation in the frequency domain [36]) increased in normal awake subjects during positive pressure ventilation at $0.05 \mathrm{~Pa}$. The small increase in BRS observed in the uncomplicated OSA patients is in line with these observations.

In this context, however, it should be emphasised that only the response to baroreflex deactivation (-PI/-SBP sequences) improved during CPAP application. This indicates an 
asymmetry in the acute improvement of BRS associated with first night CPAP application, characterised by a more prompt recovery of the reflex response to baroreceptor deactivation than to baroreceptor activation. Such a finding is not entirely surprising, as an asymmetry characterising the sensitivity of baroreflex heart rate modulation was also observed in other clinical conditions [37]. The observations during sleep appear to be in line with the selective impairment of baroreflex response to hypotensive agents found in untreated OSA during wakefulness [38]. Overall, the current study confirms that long-term CPAP treatment is necessary to reverse chronic autonomic dysfunction during sleep $[1,4,5,8]$ and wakefulness $[6,8,39,40]$, possibly in relation to recovery of cardiac vagal fibres after protracted resolution of intermittent hypoxia [41]. Thus, the autonomic dysfunction associated with severe OSA appears not to be as readily reversible as the decreased BRS in snorers [17].

Moreover, the finding that the increase in BRS did not correlate with the improvement in nocturnal $\mathrm{Sa}_{2} \mathrm{O}_{2}$ during CPAP application may also suggest that the improvement of gas exchange during CPAP and the improvement of autonomic cardiac modulation are characterised by different time constants.

Among other factors involved in the complex autonomic cardiovascular modulation in OSA, it cannot be excluded that improved sleep architecture could contribute to an increase in parasympathetic cardiac regulation. Indeed, this study confirms a partial recovery of deep sleep at first CPAP application [42]. More importantly, differences in the level and/or pattern of change in intrathoracic pressure between baseline and CPAP nights may also play some role in this setting. There is evidence that respiratory efforts can affect nocturnal BP [43]. Moreover, the overall output of aortic (intrathoracic) and carotid (extrathoracic) baroreceptors appears to be modulated by their exposure to different transmural pressures [44]. Unfortunately, this issue could only be resolved by studies in experimental animals, which would be desirable to obtain a deeper insight into such a complex topic.

Finally, this study included only a relatively small number of patients, due to the focus on uncomplicated and untreated OSA patients. The observations therefore need to be further confirmed by future studies on a larger sample of subjects.

In conclusion, in previously untreated patients with uncomplicated severe obstructive sleep apnoea, acute continuous positive airway pressure application was associated with a significant, although mild, improvement of the baroreflex control of heart rate, without any clear relationship with the improvement in nocturnal arterial oxygen saturation or apnoea/hypopnoea index. The data suggest a possible role of either central neural influences or mechanical changes in obstructive sleep apnoea-dependent autonomic modulation during continuous positive airway pressure application in explaining such an improvement. They also indicate that improvement of reflex cardiac regulation has a longer time constant than the treatment-related improvement in respiratory parameters, and that acute application of continuous positive airway pressure is not sufficient to fully revert obstructive sleep apnoea-induced baroreflex dysfunction, for which prolonged and regular treatment appears to be necessary [1].

\section{REFERENCES}

1 Bonsignore MR, Parati G, Insalaco G, et al. CPAP treatment improves baroreflex control of heart rate during sleep in severe OSAS. Am J Respir Crit Care Med 2002; 166: 279-286.

2 Parati G, Di Rienzo M, Bonsignore MR, et al. Autonomic cardiac regulation in obstructive sleep apnea syndrome: evidence from spontaneous baroreflex analysis during sleep. J Hypertens 1997; 15: 1621-1626.

3 Jo JA, Blasi A, Valladares E, Juarez R, Baydur A, Khoo MC. Model-based assessment of autonomic control in obstructive sleep apnea syndrome during sleep. Am J Respir Crit Care Med 2003; 167: 128-136.

4 Belozeroff V, Berry RB, Sassoon CS, Khoo MC. Effects of CPAP therapy on cardiovascular variability in obstructive sleep apnea: a closed-loop analysis. Am J Physiol Heart Circ Physiol 2002; 282: H110-H121.

5 Khoo MC, Belozeroff V, Berry RB, Sassoon CS. Cardiac autonomic control in obstructive sleep apnea: effects of long-term CPAP therapy. Am J Respir Crit Care Med 2001; 164: 807-812.

6 Narkiewicz K, Kato M, Phillips BG, Pesek CA, Davison DE, Somers VK. Nocturnal continuous positive airway pressure decreases daytime sympathetic traffic in obstructive sleep apnea. Circulation 1999; 100: 2332-2335.

7 Marin JM, Carrizo SJ, Vicente E, Agusti AGN. Long-term cardiovascular outcomes in men with obstructive sleep apnoea-hypopnoea with or without treatment with continuous positive airway pressure: an observational study. Lancet 2005; 365: 1046-1053.

8 Doherty LS, Kiely JL, Swan V, McNicholas WT. Long-term effects of nasal continuous positive airway pressure therapy on cardiovascular outcomes in sleep apnea syndrome. Chest 2005; 127: 2076-2084.

9 Heitmann J, Ehlenz K, Becker HF, et al. Sympathetic activity is reduced by nCPAP in hypertensive obstructive sleep apnoea patients. Eur Respir J 2004; 23: 255-262.

10 Somers VK, Dyken ME, Clary MP, Abboud FM. Sympathetic neural mechanisms in obstructive sleep apnea. J Clin Invest 1995; 96: 1897-1904.

11 Sforza E, Capecchi V, Lugaresi E. Haemodynamic effects of short-term nasal continuous positive airway pressure therapy in sleep apnoea syndrome: monitoring by a finger arterial pressure device. Eur Respir J 1992; 5: 858-863.

12 Ali NJ, Davies RJ, Fleetham JA, Stradling JR. The acute effects of continuous positive airway pressure and oxygen administration on blood pressure during obstructive sleep apnea. Chest 1992; 101: 1526-1532.

13 Dursunoglu N, Dursunoglu D, Çuhadaroglu C. Acute effects of automated continuous positive airway pressure on blood pressure in patients with sleep apnea and hypertension. Respiration 2005; 72: 150-155.

14 Logan AG, Tkacova R, Perlikowski SM, et al. Refractory hypertension and sleep apnoea: effect of CPAP on blood pressure and baroreflex. Eur Respir J 2003; 21: 241-247.

15 Fietze I, Romberg D, Glos M, et al. Effects of positivepressure ventilation on the spontaneous baroreflex in healthy subjects. J Appl Physiol 2004; 96: 1155-1160. 
16 Tkacova R, Dajani H, Rankin F, Fitzgerald FS Floras JS, Bradley TD. Continuous positive airway pressure improves nocturnal baroreflex sensitivity of patients with heart failure and obstructive sleep apnea. J Hypertens 2000; 18: 1257-1262.

17 Gates GJ, Mateika SE, Basner RC, Mateika JH. Baroreflex sensitivity in nonapneic snorers and control subjects before and after nasal continuous positive airway pressure. Chest 2004; 126: 801-807.

18 Rechtschaffen A, Kales A. A manual of standardized terminology, techniques and scoring system for sleep stages of human subjects. BIS/BRI, UCLA, Los Angeles, CA, 1968.

19 Parati G, Di Rienzo M, Bertinieri G, et al. Evaluation of the baroreceptor-heart rate reflex by 24-hour intra-arterial blood pressure monitoring in humans. Hypertension 1988; 12: 214-222.

20 Di Rienzo M, Bertinieri G, Mancia G, Pedotti A. A new method for evaluating the baroreflex role by a joint pattern analysis of pulse interval and systolic blood pressure series. Med Biol Eng Comput 1985; 23: Suppl. 1, 313-314.

21 Bertinieri G, Di Rienzo M, Cavallazzi A, Ferrari AU, Pedotti A, Mancia G. Evaluation of baroreceptors reflex by blood pressure monitoring in unanesthetized cats. Am J Physiol 1988; 254: H377-H383.

22 Parati G, Frattola A, Di Rienzo M, Castiglioni P, Pedotti A, Mancia G. Effects of aging on 24 hour dynamic baroreceptor control of heart rate in ambulant subjects. Am J Physiol 1995; 268: H1606-H1612.

23 Mancia G, Groppelli A, Di Rienzo M, Castiglioni P, Parati G. Smoking impairs baroreflex sensitivity in humans. Am J Physiol 1997; 273: H1555-H1560.

24 Gerhardt A, Vorneweg P, Riedasch M, Hohage H. Acute and persistent effect of smoking on the baroreceptor function. J Autonom Pharmacol 1999; 18: 105-108.

25 Kardos A, Watterich G, de Menezes R, Csanády M, Casadei B, Rudas L. Determinants of spontaneous baroreflex sensitivity in a healthy working population. Hypertension 2001; 37: 911-916.

26 Mancia G, Groppelli A, Casadei R, Omboni S, Mutti E, Parati G. Cardiovascular effects of smoking. Clin Exper Hypert Theory Pract 1990; A12: 917-929.

27 Groppelli A, Giorgi DAM, Omboni S, Parati G, Mancia G. Persistent blood pressure increase induced by heavy smoking. J Hypertension 1992; 10: 495-499.

28 Hla KM, Skatrud JB, Finn L, Palta M, Young T. The effect of correction of sleep-disordered breathing on blood pressure in untreated hypertension. Chest 2002; 122: 1125-1132.

29 Blevins SS, Connolly MJ, Carlson DE. Baroreceptormediated compensation for hemodynamic effects of positive end-expiratory pressure. J Appl Physiol 1999; 86: 285-293.

30 Scharf SM, Ingram RH Jr. Influence of abdominal pressure and sympathetic vasoconstriction on the cardiovascular response to positive end-expiratory pressure. Am Rev Respir Dis 1977; 116: 661-670.
31 Peters J, Hecker B, Neuser D, Schaden W. Regional blood volume distribution during positive and negative airway pressure breathing in supine humans. J Appl Physiol 1993; 75: 1740-1747.

32 Naughton MT, Rahman MA, Hara K, Floras JS, Bradley TD. Effects of continuous positive airway pressure on intrathoracic and left ventricular transmural pressures in patients with congestive heart failure. Circulation 1995; 91: 1725-1731.

33 Butler GC, Naughton MT, Rahman MA, Bradley TD, Floras JS. Continuous positive airway pressure increases heart rate variability in congestive heart failure. J Am Coll Cardiol 1995; 25: 672-679.

34 Tkacova R, Rankin F, Fitzgerald FS, Floras JS, Bradley TD. Effects of continuous positive airway pressure on obstructive sleep apnea and left ventricular afterload in patients with heart failure. Circulation 1998; 98: 2269-2275.

35 Kaye DM, Mansfield D, Aggerwal A, Naughton MT, Esler MD. Acute effects of continuous positive airway pressure on cardiac sympathetic tone in congestive heart failure. Circulation 2001; 103: 2336-2338.

36 Parati G, Di Rienzo M, Mancia G. How to measure baroreflex sensitivity: from the cardiovascular laboratory to daily life. J Hypertens 2000; 18: 7-19.

37 Pitzalis M, Parati G, Massari F, et al. Enhanced reflex response to baroreceptor deactivation in subjects with tilt-induced syncope. J Am Coll Cardiol 2003; 41: 1167-1173.

38 Narkiewicz K, Pesek CA, Kato M, Phillips BG, Davison DE, Somers VK. Baroreflex control of sympathetic nerve activity and heart rate in obstructive sleep apnea. Hypertension 1998; 32: 1039-1043.

39 Carlson JT, Hedner J, Elam M, Ejnell H, Sellgren J, Wallin BG. Augmented resting sympathetic activity in awake patients with obstructive sleep apnea. Chest 1993; 103: 1763-1768.

40 Waradekar NV, Sinoway LI, Zwillich CW, Leuenberger UA. Influence of treatment on muscle sympathetic nerve activity in sleep apnea. Am J Respir Crit Care Med 1996; 153: 1333-1338.

41 Soukhova-O'Hare GK, Cheng Z, Roberts AM, Gozal D. Postnatal intermittent hypoxia alters baroreflex function in adult rats. Am J Physiol Heart Circ Physiol (In press).

42 McArdle N, Douglas NJ. Effect of continuous positive airway pressure on sleep architecture in the sleep apneahypopnea syndrome A randomized controlled trial. Am J Respir Crit Care Med 2001; 164: 1459-1463.

43 Stradling JR, Barbour C, Glennon J, Langford BA, Crosby JH. Which aspects of breathing during sleep influence the overnight fall of blood pressure in a community population? Thorax 2000; 55: 393-398.

44 Fitzgerald RS, Robotham JL, Anand A. Baroreceptor output during normal and obstructed breathing and Mueller maneuvers. Am J Physiol 1981; 240: H721-H729. 